\title{
Rehabilitation implications of stepper exercise technique on exertion and hip extensor muscle activation-A small exploratory study
}

\author{
COL Raul Marin, MD; ${ }^{*}$ Audrey Chang, PhD; ${ }^{2}$ Tamara Cyhan, $\mathrm{RN} ;^{1}$ MAJ Phil Dinauer, MD $^{3}$ \\ ${ }^{1}$ Physical Medicine and Rehabilitation Service, ${ }^{2}$ Department of Clinical Investigations, and ${ }^{3}$ Department of Radiology, \\ Walter Reed Army Medical Center, Washington, DC
}

\begin{abstract}
This study evaluated which of two different stairstepping techniques produced a higher level of perceived physical exertion and whether magnetic resonance imaging (MRI) can identify gluteus maximus activation during stepper exercise and/ or differences in gluteus maximus activation between exercise techniques. The study was a prospective, single-blind, randomized, two-period, crossover trial. The stair-stepping techniques were 15-minute sessions of (1) short steps with arms unsupported (Short) or (2) full steps with arms supported (Full). The main outcomes measured were time to reach a rating of perceived exertion (RPE) of 13, StairMaster console intensity level, volunteers' judgment as the most strenuous technique, and gluteus maximus MRI signal intensity. We found that participants performing the Short exercise technique reached an RPE of 13 sooner (mean difference $105+/-54$ seconds, $p=0.04$ ) and were unable to reach higher StairMaster intensity levels (mean difference $2.7+/-$ $0.2, p<0.001)$. Eighty-three percent of subjects declared the Short technique more demanding $(p=0.002)$. For both group sessions, the MRI signal after exercise was higher than at rest $(p<$ 0.001). We found no MRI differences between stepping techniques. Rehabilitation and conditioning programs may benefit from the Short technique because it is perceived as a more challenging physical training activity; MRI can be used to identify metabolic muscle activation during aerobic exercise.
\end{abstract}

Key words: aerobic exercise, gluteus maximus, hip extensor, low back pain, MRI, physical exertion, rehabilitation, RPE, short-stride stepping, stepper exercise.

\section{INTRODUCTION}

Maintenance of erect posture is a coupled action that involves the back and hip extensor muscles [1-2]. The gluteus maximus is particularly important because it is a crucial link in the transfer of forces from the legs to the back [3-4]. Although the concept of hip extensor training in the management of low back pain has long been recognized, back and trunk muscle training programs, known as dynamic spinal stabilization programs, have formed the foundation of low back rehabilitation programs [5]. Hip extensor training has been gaining popularity more recently within the still evolving concept of core stabilization, which combines dynamic stabilization with functional performance [6].

Moderate or submaximal aerobic exercise has also been an integral part of low back rehabilitation programs. The rationale for the prescription of aerobic conditioning in the management of low back pain is based on its analgesic [7] and antidepressant [8] effects, its effectiveness in the long-term prevention of acute low back pain episodes [9], and its effectiveness in the management of chronic low back pain $[8,10]$. Generally speaking, lowimpact aerobic training is preferred, although the specific type of low-impact aerobic exercise is highly variable.

\footnotetext{
Abbreviations: $\mathrm{EMG}=$ electromyography, $\mathrm{MRI}=$ magnetic resonance imaging, $\mathrm{ROI}=$ region of interest, $\mathrm{RPE}=$ rating of perceived exertion, WRAMC $=$ Walter Reed Army Medical Center.

*Address all correspondence to COL Raul Marin, MD; Physical Medicine and Rehabilitation Service, Walter Reed Army Medical Center, 6900 Georgia Ave, NW, Washington, DC 20307. Email: raul.marin@na.amedd.army.mil

DOI: 10.1682/JRRD.2006.08.0105
} 
Therefore, a single exercise modality that provides the benefits of aerobic exercise while simultaneously promoting hip extensor training would be a novel and advantageous rehabilitation tool for low back pain. We believe that stepper exercise could be such a modality for the following reasons: (1) it can be a low-impact aerobic modality, (2) it is not task-specific (its aerobic and performance effects are transferable to running) [11], and (3) it can generate a longer hip extension moment during stance phase that is associated with increased overall forcegeneration of the lower-limb extensor musculature. This overall increase in force generation may be negated by the commonly used full-step arm-supported (Full) stepping technique because of the work generated by the arms through the arm rails [12]. In addition, stair climbing promotes forward lean of the upper trunk [13], which likely explains the increased duration of the hip extension moment.

To our knowledge, among the various stepping techniques (arm supported, arm unsupported, full-stride steps, short-stride steps, and their respective combinations), only two investigations have looked at metabolic demand. One group of investigators found that the arm unsupported technique produces the highest systemic metabolic demand [14], whereas the other group found that the arm supported technique decreases systemic metabolic demand only at high exercise intensities (i.e., no difference in metabolic demand at lower intensities) [15]. This inconsistency in the literature requires clarification, and thus, the degree of difficulty of full-stride versus short-stride stepping with or without arm support has yet to be described.

Electromyography (EMG) has been recognized as one of the most reliable methods of objectively measuring muscle activity and use [1,16-17]. However, Farina et al. have noted that the discriminative power of EMG depends on the location and anatomy of the muscles selected, with deeper muscles that contain coarse highthreshold motor units presenting larger limitations to EMG analysis than thin subcutaneous muscles that contain fine low-threshold motor units [18]. Furthermore, Price et al. suggested that although a muscle may be recruited by the nervous system (as identified by EMG), this recruitment may not translate into a robust metabolic workload for that muscle [19]. Alternatively, magnetic resonance imaging (MRI) is a tool that has been used to detect muscle use changes because of its effectiveness in evaluating metabolic muscle activation immediately after exercise [20-23]. Intramuscular water content changes during and after exercise lead to changes in muscle proton relaxation times that can be detected by MRI immediately after exercise $[20,23]$.

This exploratory study evaluated which of two different stair-stepping techniques caused subjects to reach a level of "somewhat hard" (rating of perceived exertion [RPE] of 13 on the Borg scale [24]) soonest and whether MRI can be used to detect metabolic gluteus maximus activation immediately after stepper (aerobic) exercise and/or discern differences in the degree of metabolic gluteus maximus activation between the two techniques. We hypothesized that (1) a short-step, arm unsupported (Short) exercise technique would elicit a higher RPE at submaximal exercise intensities, (2) postexercise MRI would be able to detect the metabolic activation of the gluteus maximus immediately after aerobic (stepper) exercise, and (3) MRI would demonstrate a higher level of metabolic activation of the gluteus maximus with the Short technique based on the longer duration hip extension moment during arm-unsupported stair climbing [12]. The results of this exploratory study could inform the feasibility of future double-blind, randomized, parallel group studies of exercise techniques with MRI versus EMG muscle assessment.

\section{METHODS}

\section{Subjects}

After providing informed consent, 24 healthy subjects (17 male, 7 female) participated in this study. Volunteers were recruited by word of mouth and from among the personnel of the Physical Therapy Service, Physical Medicine and Rehabilitation Service, and Department of Radiology at Walter Reed Army Medical Center (WRAMC). Criteria for inclusion were active duty U.S. Army individuals between the ages of 18 and 39 years with no history of low back pain, lumbar surgery, major organ system disease (cardiovascular, respiratory, renal, gastrointestinal, or neurological), sacroiliitis, radiculopathy (clinical suspicion with predominant lowerlimb pain component), spinal stenosis, dynamic pelvic stabilization exercise training, $>3 / 5$ Waddel signs (which would suggest psychological overlay), claustrophobia, or the presence of any intrinsic ferromagnetic components in their body (the last two are MRI contraindications). Active duty volunteers were considered to be equally fit 
because they are required to participate daily in a standardized physical training program based on running, flexibility exercises, and calisthenics. All volunteers had been previously exposed to the stepper to some degree, but the stepper was not their primary mode of cardiovascular training (which was running as per the mandatory physical fitness training mentioned previously). The study was approved by the Scientific Review and Human Use Committees (institutional review board) at WRAMC.

\section{Study Design}

The study design was a prospective, single-blind, two-period crossover. Participants were randomly assigned to one of two stepping exercise techniques and then crossed over to the other technique. Each testing session consisted of two 15-minute exercise periods with a 10-minute rest interval in between.

\section{Groups}

The two exercise techniques were (1) Short, which was defined as steps no bigger than half the excursion of the StairMaster ${ }^{\circledR} 4000$ PIT (StairMaster ${ }^{\circledR}$ Corporation; Vancouver, Washington) pedals with the upper body not supported by the arms on the balance bars, and (2) Full, which was defined as full excursion of the StairMaster pedals up to the mechanical stop with the upper body supported by the arms on the balance bars. A coinvestigator continually monitored the subjects' step depth on these two conditions and provided verbal cues to each subject to ensure the validity of each technique. We selected these two specific techniques because we believed that the Full technique (which appears to be the most popular in our experience) would likely engage or activate the gluteus maximus to a lesser degree than the Short technique because the latter requires the subject to maintain a more erect (i.e., less hip flexed) posture with the arms not supporting the upper body. Subjects who were randomly assigned to the Full technique followed by the Short technique sequence were referred to as the Full-Short group, and those assigned to the reverse sequence were referred to as the Short-Full group. The subjects were not told which of the two interventions had specific importance to the investigation, and the radiologist interpreting the MRI scans was blinded to the intervention assignments. All testing for each subject occurred sequentially in the same day.

\section{Experimental Procedure}

Initially, a baseline MRI (baseline scan 1) of the gluteus maximus was performed with the subject at rest. Subsequently, after a 5-minute warm-up that consisted of a standardized routine of stretching exercises, each subject began exercise session 1 on the stepper using the stepping technique (Short vs Full) assigned by the randomization schedule. The StairMaster console intensity level at which the subjects exercised was the level that provoked an RPE of 13 [24]. Cardiovascularly speaking, an RPE of 13 defines the exercise session as submaximal in nature. Thus, by instructing subjects not to exercise at intensities beyond an RPE of 13 and by monitoring how long it took to reach this level, we controlled the intensity between the groups. The original Borg scale was posted in front of the stepper at eye level. Subjects were instructed on how to rate their subjective feelings by reviewing what each set of descriptions meant (i.e., very, very light $=$ leisure walk on a flat surface; very light $=$ leisure walk up a mild to moderate incline). In addition, the "talk test" concept was explained so that if a subject is exercising and can carry on a full uninterrupted conversation, the exercise intensity is low; if the subject can carry an interrupted sentence conversation, the intensity is moderate; and if the subject cannot speak, the intensity is high. All subjects were asked to repeat back their understanding of the instructions. Although the cadence of the exercise was not directly controlled in this study, we used the StairMaster console intensity level as a proxy for cadence because the lower the intensity level, the lower the resistance and, thus, the higher the cadence [25]; therefore, cadence indirectly served as an outcome measure. Each exercise session lasted 15 minutes. Within 2 minutes of the first exercise session, we performed an MRI scan on each subject (postexercise scan 1). A 10-minute rest interval followed postexercise scan 1 and preceded the second exercise period.

Exercise session 2 began with a baseline MRI retest (baseline scan 2), after which the subjects were crossed over to the stepping technique (Short or Full) assigned by the randomization schedule. Rescanning followed immediately after this second exercise session (postexercise scan 2). Baseline scan 2 was performed for the first 11 subjects only because our intent was to identify any possible "carryover" effect on the MRI findings from the first to the second period. An interim analysis of these 11 subjects ("Results" section, p. 128) showed no differences in MRI intensity between baseline scan 1 and baseline 
scan 2, thus allowing us to streamline our testing sequence (i.e., baseline scan 1 , postexercise scan 1, postexercise scan 2) for the remaining subjects.

\section{MRI Testing Procedure}

Each subject's placement on the MRI table was clearly marked with bony landmarks (greater trochanter of the femur, acromion process of the shoulder, knee) and color tape, thus ensuring that each subsequent scan was performed with the subject laying supine in the exact position as during the first baseline scan. We used shorttau inversion recovery images with repetition time/echo time of 5,025/40 ms, inversion time of $150 \mathrm{~ms}$, and echo train length of 6 to acquire 32 axial images of the gluteal region in 4 min $45 \mathrm{~s}$ in the axial plane using a receiveonly quadrature coil. Field of view was set at $36 \mathrm{~cm}$, with an image matrix size of $256 \times 192$ pixels. A 7 mm-slice thickness and $1 \mathrm{~mm}$-interslice gap were used as a standard for each examination. Signal intensity data at fixed regions of interest (ROIs) for the gluteus maximus were identified with bony landmarks, and the mean of these ROI values for each muscle (right and left) was used for data analysis. Each ROI was drawn over an area of approximately $20 \mathrm{~mm}^{2}$ (which is equivalent to 30 pixels).

All subjects underwent MRI with a GE Signa 1.5 Tesla scanner (General Electric Company; Fairfield, Connecticut). Exercise sessions were conducted in a room adjacent to the MRI scanner.

\section{Carryover Assessment}

To avoid the common concern of carryover effect in this crossover trial, we selected the 10 -minute rest period because for resistance type exercise, 10 to 20 minutes are required for signal changes in muscle to return to baseline preexercise status [21-22]. Thus, the 7 minutes of scanning time (postexercise scan 1) plus the 10-minute rest period ensured that the signal changes attributable to the first exercise session would not be present by the onset of the second exercise session. Our study design allowed us to test this assumption as stated earlier for the first 11 subjects.

\section{Statistical Analysis}

The primary outcome variables were time (in seconds) to reach an RPE of 13 for each of the two stepping techniques, the corresponding StairMaster console intensity level at which the sessions were conducted, and the volunteers' subjective description of which technique was more strenuous. To compare the baseline characteristics between the two randomized groups (Short-Full and Full-Short), we used two-sample $t$-tests for continuous variables and Fisher exact tests for categorical variables. We also used the statistical methods described by Joseph L. Fleiss for two-period crossover designs to compare differences between the two stepper techniques and examine the carryover effect [26]. We used binomial tests to compare whether one of the techniques was perceived as more difficult. The secondary outcome variable was the MRI T2 signal intensity for the ROI on the left and right gluteus maximus. The MRI intensity data of this muscle for each exercise condition were expressed as a percentage of the initial rest condition (i.e., baseline scan 1). To assess whether MRI can discern differences between the techniques in the degree of gluteal muscle metabolic activation, we expressed the MRI intensity as the percentage of the baseline (i.e., at rest) and analyzed the data from the two-period crossover design following the methods proposed by Fleiss [26]. All tests were twotailed with a significance level set at $p \leq 0.05$. We performed all statistical analyses using SPSS for Windows, version 12.0 (SPSS Inc; Chicago, Illinois).

\section{RESULTS}

\section{Subjects}

Eleven subjects were randomized to the Short-Full group and thirteen subjects to the Full-Short group. Subject demographic data broken down by randomization group are presented in Table 1. The overall mean and standard deviation age was $31 \pm 5$ years, height was $68 \pm$ 3 inches $(173.5 \mathrm{~cm})$, and weight was $164 \pm 29$ pounds (74.7 kg). No differences were found between the groups except for weight $(p=0.03)$, with the Short-Full group being heavier than the Full-Short group. To assess whether this difference had any effect on the outcome variables, we performed analysis of covariance for crossover design; including weight as a covariate showed no effect. Neither weight nor weight $\times$ period interaction was statistically significant ( $p$-values ranged from 0.10 0.99) for all outcome variables (e.g., RPE, MRI).

\section{Primary Outcome Variables}

All subjects achieved an RPE of 13 by 10 minutes into the exercise session. Evaluation of the primary outcome variables showed that subjects exercising with the 
Short technique reached an RPE of 13 sooner than those exercising with the Full technique (mean difference $105 \pm$ 54 seconds, $p=0.04$ ), regardless of the order in which the technique was performed (i.e., Short followed by Full or vice versa) (Table 2). Likewise, subjects exercising with the Short technique were unable to reach higher StairMaster console intensity levels because of an earlier time to reach an RPE of 13 (mean difference $2.7 \pm 0.2 ; p<$ 0.001). When subjects were asked which technique was more difficult, 83 percent stated that the Short technique was more demanding or difficult than the full technique $(p=0.002)$ (Table 1).

\section{Secondary Outcome Variable}

The MRI T2 signal intensity of the baseline (rest) gluteus maximus compared with the signal intensity after exercise demonstrated a statistically significant difference $(p<0.001)$, with the postexercise MRI T2 signal being more intense. However, with regard to MRI T2 sig- nal intensity differences between techniques, we noted no statistically significant differences for either the left ( $p=$ 0.08 ) or right $(p=0.92)$ gluteus maximus, with the difference between $p$-values being due to a large variability in intensity values (Table 3 ).

\section{Carryover Analysis}

For the first 11 subjects, including members of both the Short-Full and Full-Short groups, the MRI T2 signal intensity comparison of the gluteus maximus at rest 1 (baseline scan 1) vs rest 2 (baseline scan 2) showed no statistical difference for the right $(p=0.31)$ or the left $(p=$ 0.68 ) gluteus maximus, thus confirming no carryover effect. For all 24 subjects, analyses of the main outcome variables (time to RPE of 13, StairMaster console intensity level, and MRI T2 signal intensity) in regards to carryover effect after exercise demonstrated no differences (Tables 2 and 3).

Table 1.

Subject characteristics $(n=24)$. Data presented by randomization group (Short $=$ short-step arm-unsupported stepper exercise $[n=11]$, Full $=$ full-step arm-supported stepper exercise $[n=13])$ and all subjects combined.

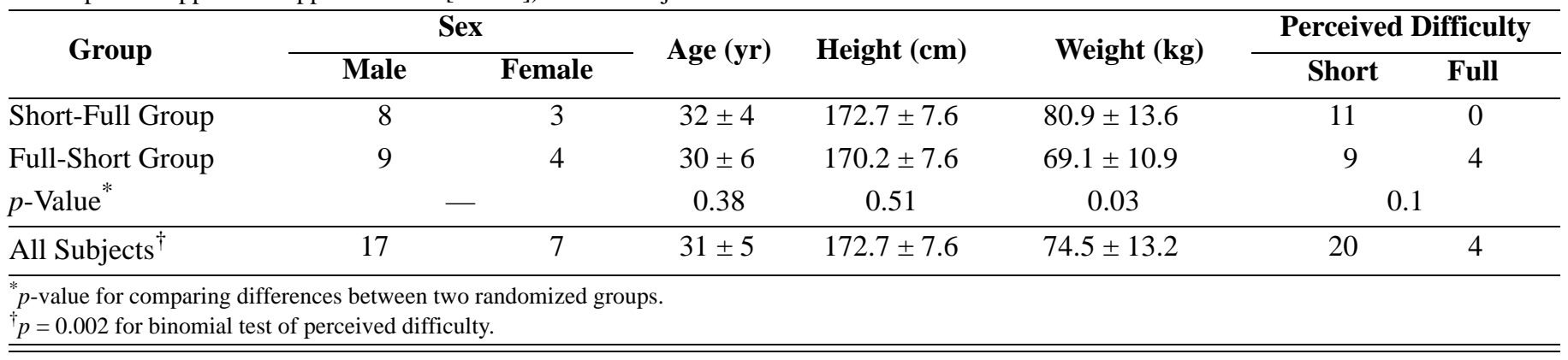

Table 2.

Mean \pm standard deviation (SD) for time to rating of perceived exertion (RPE) of 13 and console intensity by randomization group $($ Short $=$ shortstep arm-unsupported stepper exercise $[n=11]$, Full = full-step arm-supported stepper exercise $[n=13]$ ) for each exercise period.

\begin{tabular}{|c|c|c|c|c|c|}
\hline Variable & $\begin{array}{c}\text { Period } 1 \\
(\text { Mean } \pm \text { SD) }\end{array}$ & $\begin{array}{c}\text { Period } 2 \\
(\text { Mean } \pm \text { SD) }\end{array}$ & $\begin{array}{c}\text { Difference } \\
(\text { Mean } \pm \text { SD) }\end{array}$ & $\begin{array}{c}p \text {-Value* } \\
\text { (Difference) }\end{array}$ & $\begin{array}{c}p \text {-Value }{ }^{\dagger} \\
\text { (Carryover) }^{-}\end{array}$ \\
\hline \multicolumn{6}{|l|}{ Time to RPE 13 (s) } \\
\hline Short-Full Group & $349 \pm 111$ & $526 \pm 210$ & $-177 \pm 213$ & 0.04 & 0.99 \\
\hline Full-Short Group & $454 \pm 261$ & $421 \pm 250$ & $34 \pm 245$ & - & - \\
\hline \multicolumn{6}{|c|}{ Console Intensity Level } \\
\hline Short-Full Group & $8.6 \pm 2.7$ & $10.4 \pm 2.1$ & $-1.7 \pm 1.3$ & $<0.001$ & 0.69 \\
\hline Full-Short Group & $10.8 \pm 3.2$ & $7.3 \pm 2.2$ & $3.5 \pm 1.8$ & - & - \\
\hline
\end{tabular}


Table 3.

Mean \pm standard deviation (SD) for maximum magnetic resonance imaging (MRI) intensity of gluteus maximus expressed as percentage of baseline and $p$-value for comparing two interventions (Short = short-step arm-unsupported stepper exercise [n $=11]$, Full $=$ full-step armsupported stepper exercise $[n=13])$.

\begin{tabular}{|c|c|c|c|c|c|}
\hline Variable & $\begin{array}{c}\text { Period } 1 \\
(\text { Mean } \pm \text { SD) }\end{array}$ & $\begin{array}{c}\text { Period } 2 \\
(\text { Mean } \pm \text { SD) }\end{array}$ & $\begin{array}{c}\text { Difference } \\
\text { (Mean } \pm \text { SD) }\end{array}$ & $\begin{array}{c}p \text {-Value* } \\
\text { (Difference) }\end{array}$ & $\begin{array}{c}p \text {-Value }{ }^{\dagger} \\
\text { (Carryover) }^{\text {Caryon }}\end{array}$ \\
\hline \multicolumn{6}{|l|}{ Right Side } \\
\hline Short-Full Group & $123 \pm 27$ & $119 \pm 16$ & $4 \pm 21$ & 0.92 & 0.08 \\
\hline Full-Short Group & $141 \pm 33$ & $138 \pm 24$ & $3 \pm 25$ & - & - \\
\hline \multicolumn{6}{|l|}{ Left Side } \\
\hline Short-Full Group & $116 \pm 16$ & $121 \pm 19$ & $-5 \pm 19$ & 0.08 & 0.34 \\
\hline Full Short Group & $138 \pm 46$ & $117 \pm 13$ & $21 \pm 45$ & - & - \\
\hline All Subjects $(n=24)$ & \multicolumn{3}{|c|}{ Mean \pm SD } & \multicolumn{2}{|c|}{$p$-Value $^{\ddagger}$} \\
\hline \multicolumn{6}{|l|}{ Right Side } \\
\hline Rest & & \multicolumn{2}{|c|}{$<0.001$} \\
\hline Exercise & & $131 \pm 45$ & & \\
\hline \multicolumn{6}{|l|}{ Left Side } \\
\hline Rest & & $105 \pm 38$ & & \multirow{2}{*}{\multicolumn{2}{|c|}{$<0.001$}} \\
\hline Exercise & & $116 \pm 42$ & & & \\
\hline
\end{tabular}

\section{DISCUSSION}

In this prospective, single-blind, two-period crossover design exploratory study, we evaluated the capability of the Short technique to physically challenge the body and engage the gluteus maximus in the hope that our findings may prove useful regarding the feasibility of future more in-depth and detailed studies. Our two study groups were found to be identical except for the difference in weight (Table 1). This finding raises three questions: Does weight affect RPE? Does weight affect the identification of muscle use by MRI? Does the weight difference between the groups indicate that they are drawn from two different populations thus making them not comparable? Pintar et al. demonstrated that no significant interactions or body weight main effects existed for any metabolic variables, such as oxygen consumption rate, heart rate, percent maximum oxygen consumption, maximum heart rate, and RPE; only fitness level had an effect on RPE [27]. Likewise, Hulens et al. found evidence that although differences in RPE between the morbidly obese and other subjects may exist, no differences between the obese and lean subjects in regards to RPE have been reported [28]. Thus, the weight difference between our two groups should have, at most, minimal effects on RPE, particularly in view of the fact that the subjects in both groups were drawn from the same population (active duty, physically fit-by regulation - military service members from the Medical Center Brigade, WRAMC) and randomly assigned in sequential fashion during the enrollment process.

In regards to the possible effect of weight differences between the groups on muscle water content for postexercise MRI, one can only speculate. Although MRI findings can be affected by differences in muscle recruitment based on untrained versus trained status or muscle content status (slow-twitch vs fast-twitch fibers), no articles were identified in the literature addressing MRI muscle changes and differences in muscle response to exercise in two groups that differ in weight. In a study by Newcomer et al. using magnetic resonance spectroscopy, improvement in the time constant of ADP and the maximal oxidative ATP production rate were identified after weight loss [29]. Although the authors suggested that overweight women have limited mitochondrial function or oxidative metabolism, we do not know whether this metabolic difference could significantly affect muscle water content on a postexercise MRI. 
Back extension is a coupled action that involves the back and hip extensors [1-2]. In this study, we focused our assessment on the gluteus maximus because the activation of this muscle has been studied during stepper exercise with EMG [17] and because this muscle is a crucial link in the transfer of forces from the legs to the back [3-4]. Our study has demonstrated that the Short technique is perceived as more demanding than the Full technique as evidenced by subjects' inability to reach higher StairMaster console intensity levels because of the earlier onset of an RPE of 13. These objective systemic physical demand parameters (RPE and StairMaster console intensity) were supported by subjects' subjective selection of the Short technique as the more difficult of the two techniques. Our findings appear to support previous studies that showed that arm unsupported stepper exercise produces a higher metabolic demand than arm-supported stepping [14-15]. This perceived increased difficulty may be because of an inability to conserve angular momentum in the arm unsupported technique. When a person climbs a flight of stairs, the upper limbs (right leg, left arm, and vice versa) swing reciprocally so that the torque of the lower body in the vertical axis is counteracted by the torque of the upper body in the opposite direction. Likewise, during the arm-supported technique, each lower-limb push on the stepper pedal is counteracted by the contralateral upper-limb transfer of angular momentum to the handle bar. This transfer of momentum is absent in the arm unsupported technique, which may explain the increased sense of difficulty. Although this explanation is reasonable, whether the perceived higher physical challenge was due to the lack of arm support, the small steps taken, or the combination of both remains to be determined.

MRI is capable of identifying metabolic muscle activation after resistance exercise [20-23,30]. To our knowledge, this exploratory study may be among the first studies showing that MRI can also identify metabolic muscle activation during aerobic exercise, although we were unable to effectively show that MRI is sensitive enough to differentiate between the two different stepping techniques in the degree of water content change (i.e., metabolic activation). Our findings, however, do not allow for any conclusions to be made about a cutoff point at which a given percentage of postexercise MRI intensity change would equal an adequate training response. The search for such a cutoff may be a topic for future investigations.

A possible explanation for our MRI findings is found in the physiology of volumetric changes that occur in exercising muscle. These changes depend on the intensity of the exercise [31]. At submaximal workloads, extracellular water volume increases more than intracellular water volume, and at maximal workloads, the opposite is true. The higher the intracellular water content, the higher the MRI signal intensity after exercise. Although the Short technique was perceived to be the most physically demanding of the two techniques, this demand was not sufficient to increase the intracellular water content at the submaximal intensities (RPE of 13) at which the exercise was performed.

Our results have a practical relevance to the rehabilitative healthcare community. Low back pain patients have been found to have (1) increased gluteus maximus fatigability [1,32], (2) delayed firing and decreased endurance of hip extensors [1,33-35], (3) weakening of the extensor muscles versus the abdominal muscles [3435], and (4) strength imbalances between right and left gluteus maximus (a predictor of low back pain) [36]. When these dysfunctions are addressed, a decrease in the incidence, prevalence, and severity of low back pain occurs [5,37], with an associated decrease in absenteeism and workday losses [1]. Furthermore, the incorporation of aerobic conditioning into low back pain rehabilitation programs has a positive influence on the prevention [9] and management of chronic low back pain $[8,10]$ via its analgesic [7] and antidepressant [8] effects. In view of these findings, our results are clinically relevant because they suggest that stepper exercise combines the benefits of general cardiovascular training and exercise-related gluteus maximus metabolic activation into one modality. More importantly, our findings have their greatest practical relevance when the practitioner considers that the gluteus maximus plays a key role in the transfer of forces from the lower limbs to the trunk [3-4] and that this transfer of forces is part of the activities of daily living (lifting, bending over, etc.) that can exacerbate or predispose patients to low back pain.

One limitation of this study is that as an indirect measure of aerobic effort, RPE could potentially lead to misinterpretations about metabolic demand when two different exercise techniques are compared because some investigators have found that RPE may underrepresent the true aerobic demand [38]. In addition, the RPE differences noted in this study could be due to the localized peripheral muscle fatigue in the arm-unsupported group resulting from either body position or the short steps. Yet even if RPE differences were due to peripheral muscle 
fatigue, the fact remains that the arm-unsupported technique was perceived as more physically demanding, and in the context of physical training, exercising a muscle to fatigue enhances the training effect for the muscle in question. In the future, studies similar to ours should use a more objective measure of metabolic demand such as maximum oxygen consumption rate or a simple heart rate-pressure product as a way to obtain more objective data.

Finally, other limitations that should be addressed in future larger studies include (1) the use of T2 relaxation times as well as the magnitude of the signal intensity differences between rest and postexercise, (2) the calculation of effect size, (3) the inclusion of a low back pain subgroup, (4) the inclusion of a hip extensor strength control group (i.e., postisokinetic exercise or postisometric maximal voluntary contraction MRI testing), and (5) the use of stratified randomization (age, sex, weight, body mass index).

\section{CONCLUSIONS}

Stepper exercise appears to be a dual-purpose training modality that may be useful for low back pain rehabilitation because of its perceived increased training demand and its biomechanically based capacity to induce gluteus maximus metabolic activation. Our study has confirmed that the Short exercise technique is perceived as more challenging than the Full exercise technique and, thus, should be considered by rehabilitation professionals seeking to maximize the exercise difficulty when using the stepper machine as a low-impact aerobic training modality during back rehabilitation. Furthermore, our study has also confirmed that MRI can identify muscle activation during closed kinetic-chain aerobic exercise. Finally, the results of this exploratory work appear to justify further studies into this topic and, more specifically, the design of large, randomized, double-blind, parallel group studies that use maximum oxygen consumption rate as the primary outcome measure and the identification of hip and back extensor muscle activation via MRI as a secondary outcome measure.

\section{ACKNOWLEDGMENTS}

We would like to thank Dr. Jeff Gambel for his editorial support.

The StairMaster Corporation donated a StairMaster 4000 PIT machine. There were no other funding sources or donors. We had no professional relationships with the StairMaster Corporation, and they had no involvement in the study design; data collection, analysis, or interpretation; and writing or submission of this article.

The opinions and assertions contained herein are the private views of the authors and are not to be construed as official or as reflecting the views of the Department of the Army or the U.S. Government.

\section{REFERENCES}

1. Kankaanpää M, Taimela S, Laaksonen D, Hänninen $\mathrm{O}$, Airaksinen O. Back and hip extensor fatigability in chronic low back pain patients and controls. Arch Phys Med Rehabil. 1998;79(4):412-17. [PMID: 9552107]

2. Shih J, Wang YT, Moeinzadeh MH. Effect of speed and experience on kinetic and kinematic factors during exercise on a stair-climbing machine. J Sport Rehabil. 1996;5(3): 224-33.

3. Lyons K, Perry J, Gronley JK, Barnes L, Antonelli D. Timing and relative intensity of hip extensor and abductor muscle action during level and stair ambulation. An EMG study. Phys Ther. 1983;63(10):1597-1605. [PMID: 6622534]

4. Vleeming A, Pool-Goudzwaard AL, Stoeckart R, Van Wingerden JP, Snijders CJ. The posterior layer of the thoracolumbar fascia. Its function in load transfer from spine to legs. Spine. 1995;20(7):753-58. [PMID: 7701385]

5. Carpenter DM, Nelson BW. Low back strengthening for the prevention and treatment of low back pain. Med Sci Sports Exerc. 1999;31(1):18-24. [PMID: 9927005]

6. Weinstein SM, Herring SA, Standaert CJ. Low back pain. In: DeLisa JA, Gans BM, Walsh NE, editors. Physical medicine and rehabilitation: Principles and practice. Vol 1. 4th ed. Philadelphia (PA): Lippincott Williams \& Wilkins; 2004. p. 670-74.

7. Koltyn KF, Garvin AW, Gardiner RL, Nelson TF. Perception of pain following aerobic exercise. Med Sci Sports Exerc. 1996;28(11):1418-21. [PMID: 8933493]

8. Sculco AD, Paup DC, Fernhall B, Sculco MJ. Effects of aerobic exercise on low back pain patients in treatment. Spine J. 2001;1(2):95-101. [PMID: 14588388]

9. Scheer SJ, Radack KL, O’Brien DR Jr. Randomized controlled trials in industrial low back pain relating to return to 
work. Part 1. Acute interventions. Arch Phys Med Rehabil. 1995;76(10):966-73. [PMID: 7487440]

10. Van der Velde G, Mierau D. The effect of exercise on percentile rank aerobic capacity, pain, and self-rated disability in patients with chronic low-back pain: A retrospective chart review. Arch Phys Med Rehabil. 2000;81(11):1457-63. [PMID: 11083348]

11. Loy SF, Holland GJ, Mutton DL, Snow J, Vincent WJ, Hoffmann JJ, Shaw S. Effects of stair-climbing vs run training on treadmill and track running performance. Med Sci Sports Exerc. 1993;25(11):1275-78. [PMID: 8289616]

12. Nadeau S, McFadyen BJ, Malouin F. Frontal and sagittal plane analyses of the stair climbing task in healthy adults aged over 40 years: What are the challenges compared to level walking? Clin Biomech (Bristol, Avon). 2003;18(10): 950-59. [PMID: 14580839]

13. Krebs DE, Wong D, Jevsevar D, Riley PO, Hodge WA. Trunk kinematics during locomotor activities. Phys Ther. 1992;72(7):505-14. [PMID: 1409883]

14. Butts N. Effects of body position on energy costs during stairmaster exercise [abstract]. Med Sci Sports Exerc. 1993; 25(5 Suppl):S111.

15. Howley ET, Colacino D, Swensen TC. Factors affecting the oxygen cost of stepping on an electronic stepping ergometer. Med Sci Sports Exerc. 1992;24(9):1055-58. [PMID: 1406190]

16. Juker D, McGill S, Kropf P, Steffen T. Quantitative intramuscular myoelectric activity of lumbar portions of psoas and the abdominal wall during a wide variety of tasks. Med Sci Sports Exerc. 1998;30(2):301-10. [PMID: 9502361]

17. Zimmermann CL, Cook TM, Bravard MS, Hansen MM, Honomichl RT, Karns ST, Lammers MA, Steele SA, Yunker LK, Zebrowski RM. Effects of stair-stepping exercise direction and cadence on EMG activity of selected lower extremity muscle groups. J Orthop Sports Phys Ther. 1994;19(3):173-80. [PMID: 8156070]

18. Farina D, Gazzoni M, Camelia F. Low-threshold motor unit membrane properties vary with contraction intensity during sustained activation with surface EMG visual feedback. J Appl Physiol. 2004;96(4):1505-15. [PMID: 14672963]

19. Price TB, Kamen G, Damon BM, Knight CA, Applegate B, Gore JC, Eward K, Signorile JF. Comparison of MRI with EMG to study muscle activity associated with dynamic plantar flexion. Magn Reson Imaging. 2003;21(8):853-61. [PMID: 14599535]

20. Kumagai M, Shiba N, Higuchi F, Nishimura H, Inoue A. Functional evaluation of hip abductor muscles with use of magnetic resonance imaging. J Orthop Res. 1997;15(6): 888-93. [PMID: 9497815]

21. Disler DG, Cohen MS, Krebs DE, Roy SH, Rosenthal DI. Dynamic evaluation of exercising leg muscle in healthy subjects with echo planar MR imaging: Work rate and total work determine rate of T2 change. J Magn Reson Imaging. 1995;5(5):588-93. [PMID: 8574046]

22. Horrigan JM, Shellock FG, Mink JH, Deutsch AL. Magnetic resonance imaging evaluation of muscle usage associated with three exercises for rotator cuff rehabilitation. Med Sci Sports Exerc. 1999;31(10):1361-66.

[PMID: 10527305]

23. Fleckenstein JL, Watumull D, Bertocci LA, Nurenburg P, Peshock RM, Payne JA, Haller RG. Muscle recruitment variations during wrist flexion exercise: MR evaluation. J Comput Assist Tomogr. 1994;18(3):449-53.

[PMID: 8188915]

24. Borg GA. Psychophysical bases of perceived exertion. Med Sci Sports Exerc. 1982;14(5):377-81.

[PMID: 7154893]

25. MacIntosh BR, Neptune RR, Horton JF. Cadence, power, and muscle activation in cycle ergometry. Med Sci Sports Exerc. 2000;32(7):1281-87. [PMID: 10912894$]$

26. Fleiss JL. The design and analysis of clinical experiments. New York (NY): Wiley; 1986.

27. Pintar JA, Robertson RJ, Kriska AM, Nagle E, Goss FL. The influence of fitness and body weight on preferred exercise intensity. Med Sci Sports Exerc. 2006;38(5):981-88. [PMID: 16672854]

28. Hulens M, Vansant G, Claessens AL, Lysens R, Muls E. Predictors of 6-minute walk test results in lean, obese, and morbidly obese women. Scand J Med Sci Sports. 2003; 13(2):98-105. [PMID: 12641641]

29. Newcomer BR, Larson-Meyer DE, Hunter GR, Weinsier RL. Skeletal muscle metabolism in overweight and postoverweight women: An isometric exercise study using (31)P magnetic resonance spectroscopy. Int J Obes Relate Metab Disord. 2001;25(9):1309-15. [PMID: 11571592]

30. Flicker PL, Fleckenstein JL, Ferry K, Payne J, Ward C, Mayer T, Parkey RW, Peshock RM. Lumbar muscle usage in chronic low back pain. Magnetic resonance image evaluation. Spine. 1993;18(5):582-86. [PMID: 8484149]

31. Fisher MJ, Meyer RA, Adams GR, Foley JM, Potchen EJ. Direct relationship between proton T2 and exercise intensity in skeletal muscle MR images. Invest Radiol. 1990;25(5): 480-85. [PMID: 2345077]

32. Leinonen V, Kankaanpaa M, Airaksinen O, Hanninen O. Back and hip extensor activities during trunk flexion/extension: Effects of low back pain and rehabilitation. Arch Phys Med Rehabil. 2000;81(1):32-37. [PMID: 10638873]

33. Beckman SM, Buchanan TS. Ankle inversion injury and hypermobility: Effect on hip and ankle muscle electromyography onset latency. Arch Phys Med Rehabil. 1995;76(12): 1138-43. [PMID: 8540791]

34. Ito T, Shirado O, Suzuki H, Takahashi M, Kaneda K, Strax TE. Lumbar trunk muscle endurance testing: An inexpensive 
JRRD, Volume 45, Number 1, 2008

alternative to a machine for evaluation. Arch Phys Med Rehabil. 1996;77(1):75-79. [PMID: 8554479]

35. Hultman G, Nordin M, Saraste H, Ohlsèn H. Body composition, endurance, strength, cross-sectional area, and density of MM erector spinae in men with and without low back pain. J Spinal Disord. 1993;6(2):114-23.

[PMID: 8504222]

36. Nadler SF, Malanga GA, Feinberg JH, Prybicien M, Stitik TP, DePrince M. Relationship between hip muscle imbalance and occurrence of low back pain in collegiate athletes: A prospective study. Am J Phys Med Rehabil. 2001;80(8): 572-77. [PMID: 11475476]
37. Mooney V, Kron M, Rummerfield P, Holmes B. The effect of workplace based strengthening on low back injury rates: A case study in the strip mining industry. J Occup Rehabil. 1995;5(3):157-67.

38. Moyna NM, Robertson RJ, Meckes CL, Peoples JA, Millich NB, Thompson PD. Intermodal comparison of energy expenditure at exercise intensities corresponding to the perceptual preference range. Med Sci Sports Exerc. 2001; 33(8):1404-10. [PMID: 11474346]

Submitted for publication August 30, 2006. Accepted in revised form June 22, 2007. 